\title{
Fishing for Allergens: Bloodworm-Induced Asthma
}

\author{
Keith C. P. Wu, BA; Katja Räsänen, PhD; Thomas J. Hudson, MD
}

\begin{abstract}
Hypersensitivity to bloodworms (chironomid larvae) leading to asthma and other related allergic disorders is becoming common in individuals who keep or work with fish due to the increased use of bloodworms as fish food or bait.
\end{abstract}

A 37-year-old woman who was a nonsmoker presented to the allergy and asthma clinic with episodes of cough, shortness of breath, wheezing, and nasal congestion. Her symptoms seemed to worsen at her workplace, a research laboratory that studies fish biology. On a recent holiday, her symptoms completely resolved, but they recurred within a week of her returning to work. The patient later noted shortness of breath and skin rash when feeding the fish. The patient keeps no pets at home, and although there is no personal history of atopy, her father has hay fever. The physical examination was unremarkable apart from swollen turbinates. Lung function tests indicated a forced expiratory volume in 1 second $\left(\mathrm{FEV}_{1}\right)$ of $2.64 \mathrm{~L}$, and the ratio of $\mathrm{FEV}_{1}$ to forced vital capacity (FVC) was 68\%. Following salbutamol inhalation, we observed a $10 \%$ increase in $\mathrm{FEV}_{1}$ (to $2.92 \mathrm{~L}$ ) and a modest change in the $\mathrm{FEV}_{1} / \mathrm{FVC}$ ratio (to $74 \%$ ). The chest radiograph was normal, and skinprick allergy testing with common inhalant

K. C. P. Wu-Division of Clinical Immunology and Allergy, McGill University Health Centre, Montreal, Quebec; John Radcliffe Hospital, Oxford, England; K. Räsänen-Redpath Museum and Department of Biology, McGill University, Montreal, Quebec; T. J. Hudson-Division of Clinical Immunology and Allergy, McGill University Health Centre, Montreal, Quebec allergens showed positivity only to grasses. These findings were suggestive of allergic rhinitis and asthma in the workplace. Salbutamol, budesonide, and mometasone nasal spray was prescribed. The patient was also asked to keep a peak flow diary and to bring a sample of the fish food for allergy testing at the follow-up visit.

At the second visit, 1 month later, the patient reported a major reduction of symptoms. The peak flow diary (Figure 1) shows a clear relationship between two episodes of feeding the fish and

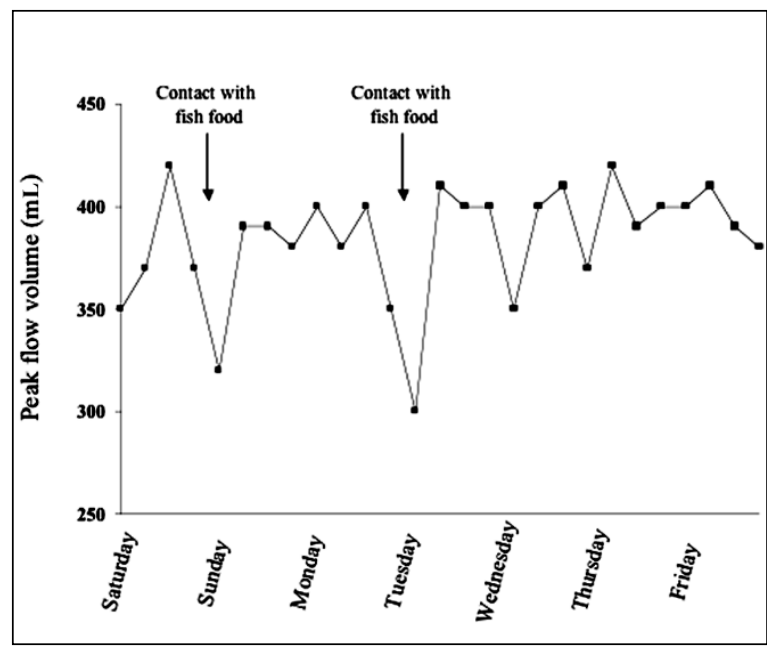

Figure 1 Graphic representation of patient's peak flow diary. 
reduced peak flow in the week following the first visit to the asthma clinic. During the subsequent 3 weeks, when feeding was delegated to other staff, she had no symptoms and peak flows were within the normal range (data not shown). Skinprick testing with a 1:2,000 dilution of the bloodworm fish food that had been brought to the clinic showed a strongly positive reaction with a $10 \mathrm{~mm}$ wheal and $32 \mathrm{~mm}$ of surrounding erythema. Lung function tests performed at the second visit showed an $\mathrm{FEV}_{1}$ of $2.87 \mathrm{~L}$ and an $\mathrm{FEV}_{1} / \mathrm{FVC}$ ratio of $79 \%$. Given the patient's clear history of exposure to bloodworms, the positive skin test result, and the disappearance of symptoms after the removal of exposure, the diagnosis of asthma and atopy from bloodworms was made.

Bloodworms, which are larvae of chironomids (also called freshwater midges), are often used as fish food or bait. Although chironomids can be found in Europe, North America, and parts of Asia, allergies to them are mainly due to their use as fish food. Individuals at particular risk of chironomid-induced allergy include fish farmers, fishermen, pet shop owners, and others who keep fish or work with fish, ${ }^{1}$ as in our patient's case.

There have been a number of previously reported cases of hypersensitivity to chironomids. ${ }^{2-4}$ With the increasing popularity of aquariums, allergy to chironomids may become less of a novelty and become something clinicians should be aware of when searching for the cause of a patient's atopic symptoms. Indeed, intradermal allergy testing of 718 asthmatic children with a Chironomidae extract in Japan showed 27.9\% of results to be positive, suggesting that atopy to chironomids is one of the most common inhalant allergies in Japan. ${ }^{5}$

\section{References}

1. Teranishi H, Kawai K, Murakami G, et al. Occupational allergy to adult chironomid midges among environmental researchers. Int Arch Allergy Immunol 1995;106:271-7.

2. Yamashita N, Morita Y, Ito K, et al. Chironomidae as a cause of $\mathrm{IgE}$-mediated histamine release in patients with asthma. Ann Allergy 1989;63:154-8.

3. Hirabayashi K, Kubo K, Yamaguchi S, et al. Studies of bronchial asthma induced by chironomid midges (Diptera) around a hypereutrophic lake in Japan. Allergy 1997;52:188-95.

4. Galindo PA, Feo F, Borja J, et al. Hypersensitivity to chironomid larvae. J Investig Allergol Clin Immunol 1998;8:219-25.

5. Adachi Y, Murakami G, Adachi Y, et al. Nationwide intradermal test with chironomid midge extract in asthmatic children in Japan. Arerugi 1990;39:670-7. 